\title{
The salmon louse genome may be much larger
}

\section{than sequencing suggests}

$7 \quad{ }^{1}$ Department of Biology, James Madison University, Harrisonburg, Virginia, United States of

8 America

$9 \quad 2$ Institute of Marine Research, Bergen, Norway

$10{ }^{3}$ Department of Arctic Marine Biology, UiT - the Arctic University of Norway, Tromsø, Norway

$12{ }^{*}$ Corresponding author

13 Email: stefano.peruzzi@uit.no

15 Keywords. Genome size variation, repetitive elements, genome assemblies, flow cytometry,

16 Feulgen image analysis densitometry

17

\section{Abstract}

19 The genome size of organisms impacts their evolution and biology and is often assumed to be

20 characteristic of a species. Here we present the first published estimates of genome size of the

21 ecologically and economically important ectoparasite, Lepeophtheirus salmonis (Copepoda,

22 Caligidae). Four independent L. salmonis genome assemblies of the North Atlantic subspecies 
23 Lepeophtheirus salmonis salmonis, including two chromosome level assemblies, yield assemblies

24 ranging from 665 - 790 Mbps. These genome assemblies are congruent in their findings, and

25 appear very complete with Benchmarking Universal Single-Copy Orthologs analyses finding

$26>92 \%$ of expected genes and transcriptome datasets routinely mapping $>90 \%$ of reads. However,

27 two cytometric techniques, flow cytometry and Feulgen image analysis densitometry, yield

28 measurements of 1.3-1.6 Gb in the haploid genome. Interestingly, earlier cytometric measurements

29 reported genome sizes of 939 and 567 Mbps in L. salmonis salmonis samples from Bay of Fundy

30 and Norway, respectively. Available data thus suggest that the genome sizes of salmon lice are

31 variable. Current understanding of eukaryotic genome dynamics suggests that the most likely

32 explanation for such variability involves repetitive DNA, which for L. salmonis makes up $\approx 60 \%$

33 of the genome assemblies.

\section{Abbreviations}

36 BUSCO - Benchmarking Universal Single-Copy Orthologs

$37 \quad$ FIAD - $\quad$ Feulgen image analysis densitometry

$38 \quad$ FCM - $\quad$ Flow cytometry

$39 \quad \mathrm{Fl}$ - $\quad$ Fluorescence

$40 \quad$ Gbp - $\quad$ Giga base pairs

$41 \quad$ Mbp - $\quad$ Mega base pairs

$42 \quad$ PI - $\quad$ Propidium iodide

43 SNP - $\quad$ Single Nucleotide Polymorphism 


\section{Introduction}

47 "In the future attention undoubtedly will be centered on the genome, and with greater appreciation

48 of its significance as a highly sensitive organ of the cell, monitoring genomic activities and

49 correcting common errors, sensing the unusual and unexpected events, and responding to them,

50 often by restructuring the genome” - Barbara McClintock’s Nobel Lecture in 1983 [1].

51 A lot has been learned since 1983, and numerous genomes have been sized, sequenced and

52 analyzed. Yet, many questions regarding genomes remain unanswered, the most fundamental

53 potentially being: why do eukaryotic genomes vary so much in size? While complexity appears to

54 correlate with minimum taxon genome size, the actual genome sizes bear no straightforward

55 correlation with eukaryotic organismal complexity, even among closely related taxa, but are

56 increasingly investigated as a trait subject to natural selection and consequently of relevance to

57 studies of ecology and evolution [2-4]. Selective pressures in copepods have been posed for age at

58 first reproduction in predation intense environments, resulting in smaller genome sizes [5], as well

59 as selection for larger bodies and genome sizes in cold environments [6,7].

60 While genome size does not appear to govern organismal complexity, some relationships appear

61 to be general: genome size often correlates with the proportion of noncoding, or repetitive, DNA

62 in the genome [8,9], cell size [2,10] and growth rate [11]. Furthermore, the evolutionary

63 importance of repetitive elements (mainly transposable elements - TEs) in lateral gene transfer

64 [12] and generation of new phenotypes [13] is becoming increasingly apparent. This is well

65 illustrated by TEs being responsible for more than 50\% of the phenotypes emerging in Drosophila

66 laboratory strains [14] and playing a role in adaptive evolution [15,16]. At the same time it must

67 be realized that species specific effects may affect genome sizes in ways that appear to be

68 inconsistent with the general trends: for example taxon specific allocation of phosphorus to RNA 
69 rather than nonessential non-coding DNA may result in a selection for compact genomes in

70 phosphorus limited environments $[17,18]$. As the role(s) of noncoding and repetitive DNA become

71 better understood, the importance of knowing to what extent this component of the genome has

72 been accurately included in the assemblies and annotations becomes increasingly clear. This does

73 not contradict the fact that partial genome assemblies may be both of high quality and immense

74 value.

75 The salmon louse (Lepeophtheirus salmonis, Krøyer 1837) is a marine parasitic copepod of

76 large economic and ecological importance [19,20]. It belongs to the order Siphonostomatoida and

77 is found on salmonid fishes in the northern hemisphere. There are two L. salmonis subspecies

78 separated by approximately 5 million years of evolution, L. salmonis salmonis (Krøyer, 1837)

79 inhabiting the North Atlantic and L. salmonis onchorhynchii [21] inhabiting the Northern Pacific

80 [21-23]. These parasites alter the physiology, disease susceptibility, growth rates, and behavior of

81 farmed salmon [24-26] and inflict large economic losses [27]. As the salmonid aquaculture has

82 expanded to the extent that farmed salmonids outnumber wild salmonids by 2-3 orders of

83 magnitude in some regions in the North Atlantic, the salmon lice populations have increased in

84 parallel and currently inflict significant economic and ecological challenges [27-28]. The

85 combined societal and ecological impacts of L. salmonis have spurred intense research, including

86 modelling to assess ecological risk [29,30], methodology for surveillance [24,31], population

87 genetics [32-34], resistance and resilience development [35,36] and molecular biology [37-40]. As

88 a result, the salmon louse genome has been sequenced several times using various sequencing

89 platforms, and independent genome assemblies have been made [40,41] - including two

90 chromosome level assemblies. 
As DNA sequencing technologies have advanced and improvements in the identification and

92 annotation of noncoding DNA have gradually followed, there is a growing awareness that genome

93 assembly methods sometimes fail to correctly reconstruct repetitive regions and noncoding DNA

94 [42,43]. Traditional quantitative cytogenetic methods such as flow cytometry and Feulgen

95 microdensitometry are recognized as being reliable with respect to estimating the true amount of

96 nuclear DNA contents and providing estimates of total genome size $[44,45]$. Thus, genomic

97 assemblies and cytometric methods possess different strengths with respect to the kinds of

98 information they provide. When these two approaches are applied in combination, they are likely

99 to either validate the independent estimates or provide direction as to seeking explanations for the

100 discrepancies. In light of the importance of the L. salmonis genome it seems prudent to use

101 cytometric methods to validate estimates from genome sequencing based estimates.

102 In the present study of the salmon louse, we compare genome size estimates based on two

103 quantitative cytometric methods (flow cytometry and Feulgen image analysis densitometry)

104 performed on multiple samples with unpublished cytometric measurements and estimates based

105 on whole genome sequencing. Where discrepancies are apparent, we propose explanations and a

106 path forward for resolving them. Additionally, as this is the first published estimate of the genome

107 size of a parasitic copepod, the genome size of this siphonostomatoid is discussed in relation to

108 the free-living copepods in the orders Cyclopoida, Calanoida, and Harpacticoida.

\section{Results}

\section{Sequencing - and assembly based genome size estimates}

112 The salmon louse genome has been sequenced several times using various sequencing platforms, 113 and six independent genome assemblies have been made - including two chromosome level 
115 linkage analyses [33,40,46], and sizes (Table 1), collectively suggesting the salmon louse genome

116 size to be approximately 600-700 Mbps.

Table 1. Key statistics and sequencing platforms for salmon louse assemblies available March 2021. Depths of sequencing coverage are the values associated with the assemblies and are estimated based on assembly-indicated genome sizes (i.e. $\approx 700 \mathrm{Mbps}$ ). The ASM18125v2 assembly is quite fragmented and the authors indicate that the assembly overestimates the actual size suggested to be around $600 \mathrm{Mbps}$ (https://www.ncbi.nlm.nih.gov/bioproject/PRJNA40179). Only LSalAtl2s is extensively assessed and the predicted gene set appears to be quite complete as it contains $92.4 \%$ of the expected genes in a BUSCO analysis and maps $\approx 90 \%$ of transcriptome 125 reads $[47,48]$.

126

\begin{tabular}{|c|c|c|c|c|c|c|c|}
\hline $\begin{array}{l}\text { Assemblies and } \\
\text { accession details }\end{array}$ & $\begin{array}{l}\text { Assembly } \\
\text { level }\end{array}$ & $\begin{array}{l}\text { Louse } \\
\text { origin }\end{array}$ & $\begin{array}{l}\text { Size } \\
(\mathrm{Mbps})\end{array}$ & $\begin{array}{l}\text { N50 } \\
\text { (Kbps) }\end{array}$ & $\begin{array}{l}\text { Sequencing } \\
\text { platform(s) }\end{array}$ & Depth & Reference \\
\hline $\begin{array}{l}\text { UVic_Lsal_1.0 } \\
\text { GCA_016086655.1 }\end{array}$ & Chromosome & Pacific & 668.1 & 48457 & $\begin{array}{l}\text { Oxford } \\
\text { Nanopore, } \\
\text { Illumina }\end{array}$ & $45 X$ & $\begin{array}{l}\text { Not } \\
\text { published*** }\end{array}$ \\
\hline $\begin{array}{l}\text { UStir_LSAA } \\
\text { PRJEB43242 }\end{array}$ & Chromosome & Atlantic & $\begin{array}{l}632.5 \\
609.3^{*}\end{array}$ & $\begin{array}{l}5100 \\
43017 * *\end{array}$ & PacBio & $107^{* *}$ & $\begin{array}{l}\text { Not } \\
\text { published*** }\end{array}$ \\
\hline $\begin{array}{l}\text { LSalAtl2S } \\
\text { licebase.org }\end{array}$ & Scaffold & Atlantic & 695.4 & 478 & $\begin{array}{l}\text { Illumina HiSeq, } \\
\text { 454, Sanger } \\
\text { fosmid end }\end{array}$ & $175 X$ & [40] \\
\hline $\begin{array}{l}\text { Atlantic female } \\
\text { GCA_001005205.1 }\end{array}$ & Scaffold & Atlantic & 665.1 & 16 & Illumina HiSeq & $45 X$ & $\begin{array}{l}\text { Not } \\
\text { published*** }\end{array}$ \\
\hline $\begin{array}{l}\text { Atlantic male } \\
\text { GCA_001005235.1 }\end{array}$ & Scaffold & Atlantic & 665.3 & 13 & Illumina HiSeq & $55 X$ & $\begin{array}{l}\text { Not } \\
\text { published*** }\end{array}$ \\
\hline $\begin{array}{l}\text { ASM18125v2 } \\
\text { GCA_000181255.2 }\end{array}$ & Scaffold & Pacific & 790.1 & 10 & Illumina, 454 & $88 \mathrm{X}$ & [41] \\
\hline
\end{tabular}

*The UStir_LSAA assembly comprised 158 sequences in total, 15 of which were identified as 128 chromosomes. The value denoted ' $*$ ' is the assembly size for these 15 chromosomes. ${ }^{* *}$ Calculated 129 based on the $632.5 \mathrm{Mbp}$ assembly size. ***Unpublished assemblies available in public repositories 130 were included with permission from the assembly authors in adherence to the Fort Lauderdale 131 agreement [49].

To evaluate the congruence of the assemblies, while not requiring them to conserve synteny,

134 we created libraries of 240 bp synthetic reads from each of the assemblies. These synthetic reads

135 were then mapped to each of the published assemblies using BLAST. The results show that the 136 assemblies are close to interchangeable in terms of their sequence composition (Table 2) and that

137 the differences in the sequence captured by the different sequencing technologies are minor. 
Table 2. Consistency of assemblies. The assemblies were converted to $240 \mathrm{bp}$ synthetic reads that were blasted against all other assemblies. The assemblies from which synthetic reads originated are indicated in column headings and the reference assemblies are indicated in the row headings. The results show average query cover \% and (the proportion of reads that maps with $>95 \%$ 143 identity).

\begin{tabular}{|c|c|c|c|c|c|c|}
\hline & ASM18125v2 & $\begin{array}{l}\text { Atlantic } \\
\text { female }\end{array}$ & Atlantic male & UVic_Lsal_1.0 & UStir_LSAA & LSalAtl2S \\
\hline $\begin{array}{l}\text { ASM18125v2 } \\
\text { GCA_000181255.2 }\end{array}$ & & $\begin{array}{l}97.74 \% \\
(0.90)\end{array}$ & $\begin{array}{l}96.90 \% \\
(0.90)\end{array}$ & $\begin{array}{l}96.17 \% \\
(0.97)\end{array}$ & $\begin{array}{l}97.12 \% \\
(0.88)\end{array}$ & $\begin{array}{l}97.50 \% \\
(0.88)\end{array}$ \\
\hline $\begin{array}{l}\text { Atlantic female } \\
\text { GCA_001005205.1 }\end{array}$ & $\begin{array}{l}93.77 \% \\
(0.88)\end{array}$ & & $\begin{array}{l}97.85 \% \\
(0.98)\end{array}$ & $\begin{array}{l}93.67 \% \\
(0.89)\end{array}$ & $\begin{array}{l}97.22 \% \\
(0.95)\end{array}$ & $\begin{array}{l}96.97 \% \\
(0.93)\end{array}$ \\
\hline $\begin{array}{l}\text { Atlantic male } \\
\text { GCA_001005235.1 }\end{array}$ & $\begin{array}{l}94.01 \% \\
(0.88)\end{array}$ & $\begin{array}{l}98.90 \% \\
(0.98)\end{array}$ & & $\begin{array}{l}94.06 \% \\
(0.89)\end{array}$ & $\begin{array}{l}97.36 \% \\
(0.95)\end{array}$ & $\begin{array}{l}96.99 \% \\
(0.93)\end{array}$ \\
\hline $\begin{array}{l}\text { UVic_Lsal_1.0 } \\
\text { GCA_016086655.1 }\end{array}$ & $\begin{array}{l}96.44 \% \\
(0.97)\end{array}$ & $\begin{array}{l}98.31 \% \\
(0.91)\end{array}$ & $\begin{array}{l}97.52 \% \\
(0.91)\end{array}$ & & $\begin{array}{l}98.13 \% \\
(0.89)\end{array}$ & $\begin{array}{l}98.12 \% \\
(0.89)\end{array}$ \\
\hline $\begin{array}{l}\text { UStir_LSAA } \\
\text { PRJEB43242 }\end{array}$ & $\begin{array}{l}93.48 \% \\
(0.87)\end{array}$ & $\begin{array}{l}97.47 \% \\
(0.97)\end{array}$ & $\begin{array}{l}96.59 \% \\
(0.97)\end{array}$ & $\begin{array}{l}93.75 \% \\
(0.88)\end{array}$ & & $\begin{array}{l}97.74 \% \\
(0.95)\end{array}$ \\
\hline $\begin{array}{l}\text { LSalAtl2S } \\
\text { licebase.org }\end{array}$ & $\begin{array}{l}94.56 \% \\
(0.89) \\
\end{array}$ & $\begin{array}{l}98.58 \% \\
(0.97) \\
\end{array}$ & $\begin{array}{l}97.59 \% \\
(0.97) \\
\end{array}$ & $\begin{array}{l}94.80 \% \\
(0.89)\end{array}$ & $\begin{array}{l}98.57 \% \\
(0.96)\end{array}$ & \\
\hline
\end{tabular}
size [9] and additional sequence-based genome size estimates were therefore produced. First, k-

151 published data from wild salmon lice [33] and using the word lengths of 29 and 31 yielded

152 estimated genome sizes of 1086 and 1015 Mbps (modal k-mer coverages: 55 and 53).

153 Second, sequencing reads were mapped to the LSalAtl2s genome using BWA [51]. For each

154 library, modal coverage (M) was extracted, and assumed to be representative of diploid coverage.

155 All coverages for the genome were then summed and divided by the modal coverage to estimate

156 the genome size. Under the assumption that repeat sequence occurring $\mathrm{N}$ times in the genome

157 would have a coverage distribution centered on $\mathrm{N}^{*} \mathrm{M}$, each location in the repeat would be counted

$158 \mathrm{~N}$ times. Seven inbred salmon lice libraries [40] were used, with modal coverages of 3-23x, and

159 resulting in genome size estimates of 791-1184 Mbps, with low coverage libraries giving the 

coverages of 5-17x, and size estimates of 845-1073, again with low coverage libraries leading to higher size estimates.

\section{Genome size estimates based on FCM}

165 The nuclear DNA contents of somatic (2C values) and gametic cells measured by flow cytometry

166 (FCM, Runs 1-5) in gametic, naupliar or adult stages of Atlantic L. salmonis salmonis are reported (CVs) in the range of 1-5\% (Table 3).

Table 3. Nuclear DNA contents of somatic and gametic cells of L. salmonis salmonis as measured using flow cytometry. Runs 1, 2, 3, and 5 measured somatic cells of nauplii or adults of the LsTromsø strain. Run 4 measured gametic cells of the Ls Gulen laboratory strain. Run 5 compared the laboratory reared LsTromsø strain to wild caught adults from naturally infected fish reared in Tromsø. Chicken and/or human white blood cells were used as internal reference standards. CEN $=$ Chicken erythrocyte nuclei ( $2 C$ value $=2.5$ pg DNA per nucleus), $\mathrm{MNCs}=$ human mononucleated cells $(2 \mathrm{C}$ value $=7.0 \mathrm{pg}$ DNA per nucleus), $\mathrm{WB}=$ whole body, $\mathrm{CT}=$ cuticular and subcuticular tissues from cephalic region, $\mathrm{O}=$ oocytes, $\mathrm{S}=$ sperm, $\mathrm{N}=$ number of individuals or number of samples in the cases of nauplii analyzed, $\mathrm{CV}=$ Coefficient of Variation as a percentage of mean for target nuclei (L. salmonis data). $\mathrm{Na}=$ not available. For naupliar stages (Run 1 and 2), each sample consisted of approximately 50 nauplii. *Average value based on the two internal 183 standards. For Run 5, 2C values with superscripts "a" and "b" differ at $\mathrm{P}<0.05$ (two-way 184 ANOVA).

185

\begin{tabular}{|c|c|c|c|c|c|c|c|c|}
\hline Run & Origin & Stage & Tissue & $\mathbf{N}$ & $\begin{array}{l}2 C \text { value (pg) } \\
\text { vs. CEN } \\
\text { Mean } \pm \text { SEM }\end{array}$ & $\begin{array}{l}2 C \text { value (pg) } \\
\text { vs. MNCs } \\
\text { Mean } \pm \text { SEM }\end{array}$ & $\begin{array}{l}\text { CV } \\
(\%)\end{array}$ & $\begin{array}{l}2 C \\
\text { value } \\
\text { (Gb) }\end{array}$ \\
\hline 1 & LsTroms & Nauplii & WB & 10 & $3.08 \pm 0.009$ & na & $2-4$ & 3.01 \\
\hline 2 & LsTromsø & Nauplii & WB & 11 & $3.09 \pm 0.005$ & $3.06 \pm 0.021$ & $2-3$ & $3.01 *$ \\
\hline \multirow{2}{*}{3} & \multirow{2}{*}{ LsTromsø } & Adult + & CT & 3 & $3.10 \pm 0.020$ & $3.12 \pm 0.008$ & $3-5$ & $3.04 *$ \\
\hline & & Adult ふ઼ & CT & 6 & $3.14 \pm 0.139$ & $3.14 \pm 0.010$ & $3-5$ & $3.07 *$ \\
\hline 4 & LsGulen & Adult + & $\mathrm{O}$ & 5 & $3.36 \pm 0.003$ & $3.31 \pm 0.003$ & $2-4$ & $3.26^{*}$ \\
\hline
\end{tabular}




\begin{tabular}{|c|c|c|c|c|c|c|c|c|}
\hline & & Adult $\widehat{0}$ & S & 5 & $1.69 \pm 0.006$ & $1.68 \pm 0.002$ & $1-3$ & $1.65^{*}$ \\
\hline \multirow{4}{*}{5} & LsTromsø & Adult $q$ & CT & 5 & $3.01^{b} \pm 0.022$ & na & $2-3$ & 2.94 \\
\hline & LsTromsø & Adult ふָ & CT & 5 & $3.19^{a} \pm 0.016$ & na & $3-4$ & 3.12 \\
\hline & Wild & Adult $q$ & CT & 11 & $3.08^{b} \pm 0.031$ & na & $2-3$ & 3.01 \\
\hline & Wild & Adult $\hat{\sigma}$ & CT & 5 & $3.19^{a} \pm 0.013$ & na & $3-5$ & 3.12 \\
\hline
\end{tabular}
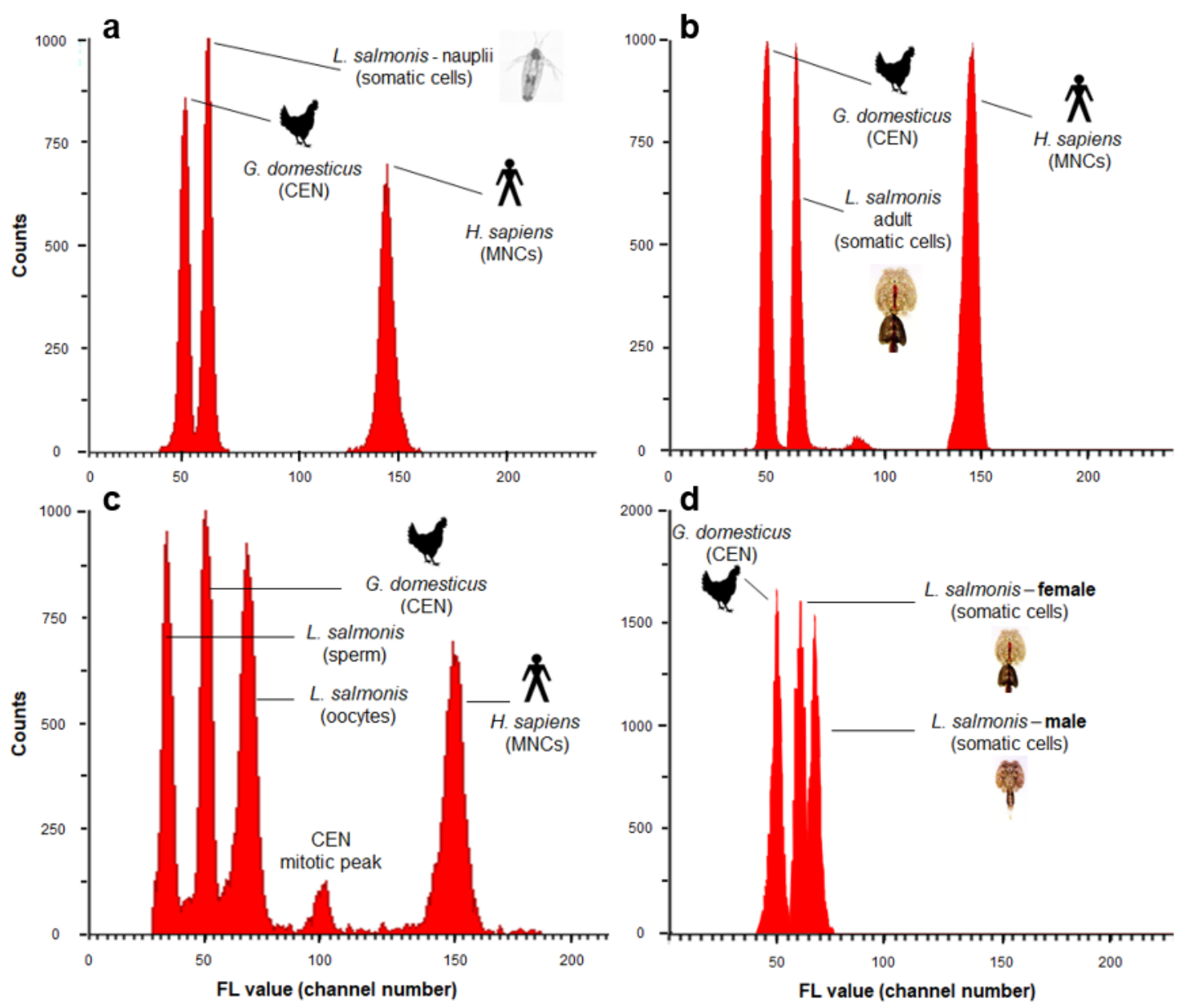

Figure 1. Representative fluorescence histograms of PI-stained somatic and gametic cells of $L$. salmonis salmonis. (a) Run 1, somatic cells obtained from whole body squash of nauplii; (b) Run 3, somatic cells obtained from cephalic regions of adult females; (c) Run 4; oocyte and sperm samples; (d) Run 5, somatic cells obtained from cephalic regions of adult males and females. Samples analyzed using chicken and human cells as internal reference standards. Fluorescence (FL) peaks values on the X-axis are reported in arbitrary units expressed as Propidium Iodide (PI) fluorescence channel numbers (FL value). Values on the Y-axis (counts) refer to the number of nuclei counted per channel. CEN = chicken erythrocytes nuclei, MNCs = human mono-nucleated cells. 
The estimated 2C DNA contents of somatic cells in naupliar stages of Ls Tromsø were similar

198 across replicates (FCM Runs 1 and 2), averaging 3.08 pg DNA per nucleus when using chicken

199 (CEN) as an internal standard (Table 2) and did not vary significantly when both chicken and

200 human (MNCs) standards were used simultaneously (FCM Run 2). Nauplii cannot visually be

201 assigned a sex and thus it cannot be known for certain what sex ratio occurred in these samples

202 although sex is genetically determined with a 50:50 ratio [40].

203 The average nuclear 1C DNA contents of Ls Gulen sperm cells (FCM Run 4) were 1.68 and

2041.69 pg DNA per nucleus, and did not differ when estimated using chicken or human standards.

205 The estimated 2C value of oocytes (FCM Run 4) averaged 3.33 pg DNA per nucleus with no

206 significant difference between values based on the two standards. A derived $2 C$ value of sperm

207 cells (twice the 1.69 pg DNA per sperm cell) does not differ significantly from that of the

208 unfertilized oocytes, 3.33 pg DNA per nucleus (Table 2).

209 The nuclear DNA contents of males and females in both wild caught and laboratory reared

210 Tromsø strains were compared in Run 5. The 2C DNA content of somatic cells averaged 3.01 and

2113.19 pg DNA/nucleus in female and male specimens of a laboratory strain, respectively. The same

212 trend was observed when analyzing somatic cells of wild specimens; the $2 C$ values averaging 3.08

213 and 3.19 pg DNA per nucleus in females and males, respectively. Overall, within this FCM run

214 male genome size estimates were consistently larger (ANOVA, $\mathrm{P}=0.0001$ ) that female genome

215 size estimates whereas, the 2C DNA contents of somatic cells within a gender did not differ

216 significantly between salmon lice of different origin and with no interaction between the two

217 factors. Despite the lack of a statistically significant difference between male and female adults of

218 laboratory reared Ls Tromsø salmon lice recorded in FCM Run 3, the DNA content of these 
219 somatic cells did not significantly differ from the laboratory and wild caught adults measured in

220 Run 5, when comparisons were made within gender.

221

222 Feulgen image analysis densitometry (FIAD) - Nuclear morphologies of

\section{3 somatic tissues}

224 The squashed somatic tissues possessed a variety of nuclear morphologies, from dense to diffuse

225 (Fig. 2), which yielded a corresponding variety of values of integrated optical density (IOD). Such

226 heterogeneity in nuclear morphology was not observed in either chicken or trout erythrocyte

227 standards (Fig. 2a,b). We made decisions to select for measurement nuclei with intermediate

228 morphologies that possessed a granular and slightly diffuse appearance (Fig. 2c,d). Nuclei that

229 were very densely staining in appearance, or compact (Fig. 2e), yielded IOD values at the lower

230 end of the range, possibly due to DNA compaction. Nuclei with a very diffuse appearance and

231 sometimes with nuclear membranes possessing uneven edges that might indicate partial

232 degradation (Fig. 2f), tended to possess IOD values at the higher end of the range. The

233 corresponding 2C values were 2.1 pg DNA per nucleus for densely stained nuclei to 3.4 pg DNA

234 per nucleus for diffuse nuclei. 

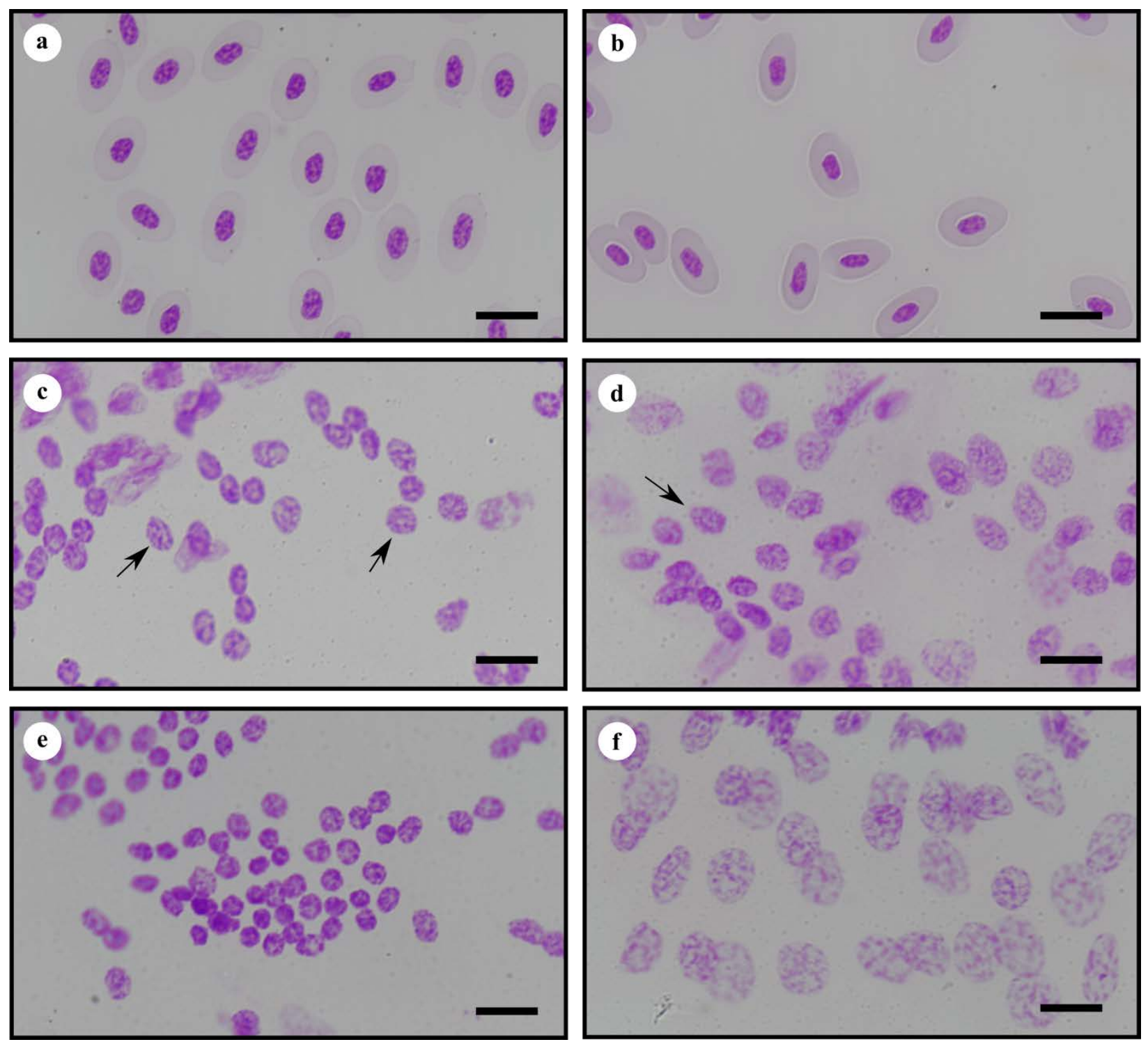

Figure 2. Photomicrographs of squash preparations of somatic nuclei of cephalothorax of $L$. salmonis salmonis and erythrocytes of hen and trout used as standards, stained with Feulgen reaction for DNA. (a) Nuclei of erythrocytes of G. domesticus; (b) Nuclei of erythrocytes of $O$. mykiss; (c) Representative nuclei, indicated by arrows, of male $L$. salmonis salmonis slide 64 whose measurements are given in Table 4; (d) Representative nucleus, indicated by arrow, of female $L$. salmonis salmonis slide 63 whose measurements are given in in Table 4; (e) Nuclei of male $L$. salmonis salmonis slide 64 with high level of DNA compaction; (f) Nuclei of male L. salmonis salmonis slide 64 with highly diffuse morphology. Scale bars represent $10 \mu \mathrm{m}$.

\section{Genome sizes based on FIAD}


standard, the average somatic nuclear DNA contents of individual adult males $(2.86-2.93 \mathrm{pg}$

DNA per nucleus) were consistently larger than the average nuclear DNA contents of individual

251 the average of three individual males, $2.90 \mathrm{pg}$ of DNA per nucleus (Table 4). The two sample $t$

252 tests were based on 3 individuals per sex, rather than 120 nuclei per sex (Table 4; the $\mathrm{N}$ values

253 for LsGulen), to avoid pseudoreplication.

Table 4. Nuclear DNA contents of somatic cells of individual adult $L$. salmonis as measured using Feulgen image analysis densitometry. Cephalothorax (CT) tissues of laboratory reared adults were obtained from the $L s$ Gulen and $L s 1$ a populations. Tissue from the spine of an appendage (SP) was obtained from a wild caught Maine population. Hen (CEN) and male human mononucleated leucocytes (MNCs) were used as internal reference standards to estimate values in picograms (pg). 260 Values based on hen were converted to gigabases (Gb). N refers to number of nuclei measured in each adult. SEM refers to standard error of the mean; CV refers to coefficient of variation of IOD values.

\begin{tabular}{|c|c|c|c|c|c|c|c|}
\hline Origin & Stage & Tissue & $\mathbf{N}$ & $\begin{array}{l}2 C \text { value (pg) } \\
\text { vs. CEN } \\
\text { Mean } \pm \text { SEM }\end{array}$ & $\begin{array}{l}2 C \text { value (pg) } \\
\text { vs. MNCs } \\
\text { Mean } \pm \text { SEM }\end{array}$ & $\begin{array}{l}\text { CV } \\
(\%)\end{array}$ & $\begin{array}{l}2 C \\
\text { value } \\
\text { (Gb) }\end{array}$ \\
\hline \multicolumn{8}{|l|}{ Laboratory } \\
\hline Ls Gulen 61 & Adult $q$ & CT & 13 & $2.78 \pm 0.012$ & na & 1.6 & 2.74 \\
\hline Ls Gulen 62 & Adult + & CT & 15 & $2.64 \pm 0.003$ & na & 3.3 & 2.60 \\
\hline Ls Gulen 63 & Adult $q$ & CT & 92 & $2.67 \pm 0.003$ & na & 10.4 & 2.63 \\
\hline Average & & & & $2.70 \pm 0.043$ & na & & 2.66 \\
\hline Ls1a 133 & Adult $q$ & CT & 34 & $2.64 \pm 0.046$ & $2.60 \pm 0.046$ & 10.2 & 2.60 \\
\hline Ls1a 134 & Adult $q$ & CT & 20 & $2.75 \pm 0.037$ & $2.71 \pm 0.037$ & 6.1 & 2.67 \\
\hline Ls1a 137 & Adult + & CT & 16 & $2.71 \pm 0.025$ & $2.67 \pm 0.025$ & 3.9 & 2.65 \\
\hline Average & & & & $2.70 \pm 0.032$ & $2.66 \pm 0.032$ & & 2.66 \\
\hline Ls Gulen 64 & Adult $\hat{0}$ & CT & 65 & $2.93 \pm 0.035$ & na & 9.9 & 2.89 \\
\hline Ls Gulen 65 & Adult $\widehat{\sigma}$ & CT & 36 & $2.86 \pm 0.037$ & na & 7.9 & 2.82 \\
\hline Ls Gulen 66 & Adult $\hat{\sigma}$ & CT & 19 & $2.90 \pm 0.054$ & na & 8.3 & 2.85 \\
\hline Average & & & & $2.90 \pm 0.020$ & na & & 2.85 \\
\hline Wild & & & & & & & \\
\hline $\begin{array}{l}\text { Copscook } \\
\text { Bay, Maine }\end{array}$ & Adult $q$ & SP & 3 & $3.07 \pm 0.176$ & na & 9.8 & 3.00 \\
\hline
\end{tabular}


264 A single wild caught adult female collected from a Maine population possessed nuclei in an

265 appendage that were especially well suited for measurement as they were well isolated and lacked

266 any visible background stain. The mean value of these nuclei, 3.07 pg DNA per nucleus, does not

267 differ from the wild female that was caught near Tromsø nor from the laboratory reared Ls Tromsø

268 strain (Tables 3, 4). It should be noted that the Maine specimen was squashed and stained as above,

269 but prior to employing the freeze cracking technique, and thus measurements were restricted to

270 those few nuclei in the spine of a swimming leg that possessed a granular and slightly diffuse

271 appearance, and were also isolated and surrounded by clear background.

272

273 Comparison of genome size estimates based on FIAD and FCM

274 Estimated 2C genome sizes of male and female laboratory reared Ls Gulen adults obtained using

275 FIAD and based on the chicken standard (2.90 and 2.70 pg DNA per nucleus, respectively, Table

276 4) are within 10\% of the estimates obtained using FCM on the Ls Tromsø laboratory strain (Table

277 3), assuming values of 3.2 and 3.0 pg DNA per nucleus for males and females, respectively, for

278 the Ls Tromsø strain). Each slide containing a population of nuclei from a single adult in the FIAD

279 analyses contained some values that overlapped with estimates obtained using FCM; however,

280 these higher FIAD values did not equal the central tendency of values obtained using FCM. The

281 average nuclear DNA content obtained for the Ls Gulen adult females using FIAD, 2.70 pg DNA

282 per nucleus, is within the $15 \%$ range of the value based on oocytes 3.26 pg DNA per nucleus (FCM

283 run 4). 


\section{Discussion}

L. salmonis assemblies are consistently approximately 700 Mbps suggesting that the L. salmonis

$2891 C$ genome may be of approximately the same size, or possibly larger if the assemblies include

290 substantial collapsed repeated regions. This approximate size was readily accepted by the salmon

291 louse research community, as the first cytometric based estimate of a North Atlantic population

292 was $0.58 \mathrm{pg}(\approx 567 \mathrm{Mbps})$ [52]. Thirteen years later a Bay of Fundy population measured in the

293 same lab was estimated to be $0.96 \mathrm{pg}(\approx 939 \mathrm{Mbps})[53]$. Yet in the present study the L. salmonis

294 subsp. salmonis genome size estimates range from 1.3 to 1.6 Gbps when determined by two

295 independent cytometric methods being applied to three laboratory strains and wild salmon lice

296 from two locations. Sequence based extrapolations, in contrast, yield estimates ranging between

$297 \quad 0.8$ and 1.2 Gbps. In attempting to identify the factors responsible for the different estimates of $L$.

298 salmonis salmonis genome size, we emphasize the importance of harnessing complementary

299 approaches to estimate genome size and where discrepancies exist, not to disregard potentially

300 'missing' portions of DNA which may play an important role in adaptation. Additionally, while it

301 is a common bias to interpret 'old measurements' as wrong when they disagree with new

302 measurements, we remain open to a plethora of explanations to reconcile older and present study

303 findings based on cytometric methods.

304 Genome assembly sizes are known to be unreliable predictors for genome size. Highly

305 conserved repeats in combination with read errors can be difficult to resolve, and assemblies can

306 have repeated regions collapsed into one sequence or have multiple copies of the same genomic

307 region. More precise estimates can be achieved by examining the sequence reads. We have used

308 two approaches, one using k-mer statistics and another based on mapping statistics against a

309 reference assembly. These methods point to a genome size of 800-1200 based on mapping, and 
1000-1100 Mbp based on k-mers. One partial explanation for the variability can be unmapped

311 reads (approximately 5\% of the reads). If they represent sequence not present in the genome

312 assembly, these genome components will be omitted from the mapping estimate, but included in

313 the k-mer estimate. In addition, most of the sequence data is from female salmon lice, and both

314 approaches will count the average of the haploid sex chromosomes, not their sum.

315 Flow cytometry is a well-established method for nuclear DNA content analysis and 316 characterization in experimental biology, and is increasingly being used due to its rapidity, 317 precision, and reproducibility. Feulgen image analysis densitometry similarly has experienced a 318 resurgence in its use, partially due to its affordability and applicability when the number of 319 available nuclei to measure is small. Interpretations of genome size estimates based on FCM and 320 FIAD require careful consideration of the advantages and disadvantages of each method for the 321 species and specific tissues under consideration. Explanations of differences among cytometric 322 measurements in general, as well as those in the present study with unpublished estimates [52,53], 323 performed on L. salmonis could include tissue compaction levels that can cause estimates to vary 324 two-fold, misidentification of haploid and diploid cells, and misidentification of species, the latter

325 of which seems quite unlikely as species identifications were provided by external expert 326 collaborators. Not to be discounted is the possibility of real variation in genome size among 327 populations. Jeffrey’s [53] review highlights the issues of concern, particularly the chemistries 328 and tissues measured most applicable to the present study, and are discussed in Supplemental 329 Methods.

330 Measurements of nuclear DNA contents of naupliar and/or adult stages of two laboratory strains 331 and wild caught L. salmonis salmonis based on FCM and two laboratory strains and one wild 332 caught population of adults stages based on FIAD estimate $2 C$ somatic nuclear contents to be $3 \pm$ 
$0.3 \mathrm{~Gb}$. Halving the FCM values to obtain the $1 C$ amount and directly measuring sperm DNA

334 content yielded values ranging from 1.47 - 1.65 Gb (Table 3). Gametic nuclei of L. salmonis

335 salmonis contained one half the DNA of the somatic nuclei, and indicates a lack of chromatin

336 diminution, a phenomenon in which $1 C$ values cannot be estimated by halving somatic genome

337 sizes [54].

338 Male genome size was consistently slightly larger than female genome size, expectedly so due

339 to erosion of the W-chromosome in the heterozygotic female [55]. There was also no evidence of

340 mitoses in the adult somatic tissues, and therefore most adult somatic cells are suitable for genome

341 size measurement [56]. Furthermore, we found no evidence of significant differences based on

342 cytometric based comparisons of geographical (Norway, Maine), laboratory (Ls1a, Ls Gulen and

343 Ls Tromsø) or wild caught (Norway, Maine) populations.

344 Genome size estimates of crustaceans based on FIAD are commonly lower than those based on

345 FCM and estimates within 15\% of one another are generally considered reliable [53]. Accordingly,

346 the FIAD derived estimates of 2.7 and 2.9 pg DNA per nucleus for adult females and males

347 respectively, are within $10 \%$ to $15 \%$ lower than the FCM based estimates, depending upon the

348 particular comparison. The most likely explanation for the disparity between FCM and FIAD

349 based estimates is that the laser detection of cells in a suspension used in FCM is less sensitive to

350 background noise, DNA compaction and other conformational changes in the chromatin

351 sometimes encountered when measurements are based on the quantitative intercalation of the

352 Schiff reagent among nucleotides as they sometimes are in squashed tissues in FIAD. These

353 differences between FCM and FIAD based estimates of adults correspond to approximately 0.3 pg

354 in a $2 \mathrm{C}$ nucleus, or $\approx 150$ million base pairs in the $1 C$ genome. We conclude that measurements

355 obtained from FIAD and FCM were internally consistent and that the discrepancy between the 
356 results are well within the boundaries expected from earlier studies [57]. Since cytometric

357 measurements are based on direct observations and the derived estimates are both consistent within

358 the methods and discrepancies in accordance with methodological expectations we regard the

359 cytometric results, collectively indicating a L. salmonis salmonis genome size of approximately

3601.5 Gbps, as the most reliable measurements available.

361 The above suggests that sequence based methods underestimate the genome size by 362 approximately $1 / 3^{\text {rd }}$. The mapping approach is sensitive to errors in assembly completeness, 363 uniformity of library and sequencing coverage, mapping accuracy and modal mapping estimation.

364 Alas, our analysis did not reveal which of these factors were the more likely to cause the apparent 365 mapping based underestimation of genome size. As an alternative to the mapping based estimates 366 we applied the widely used k-mer approach which similarly appeared to miss approximately $1 / 3^{\text {rd }}$ 367 of the genome size. The most plausible explanation may be that repetitive elements cause the k368 mer approach to underestimate genome size as previously observed by Pflug and co-workers [58].

369 Similarly, genome assembly based on k-mer analysis of the lobster Homarus americanus is 370 believed to be missing approximately $28 \%$ of the genome [59]. The salmon louse genome is among 371 the crustaceans with highest occurrence of repetitive elements; $\approx 60 \%$ of the assembly annotated

372 as repeats [40], suggesting that such underestimation of size may not be implausible. In the present 373 study sequence based genome size estimates consistently provided substantially lower genome 374 size estimates than cytometric measurements. Hence estimates should be regarded with caution 375 until they have been confirmed by direct cytological measurements.

376 While our cytometric based estimates converge on a genome size of approximately 1.5 Gbps, 377 earlier cytometric measurements disagree: a $1 C=0.58$ pg DNA per cell (567 Mbp) estimate by 378 Gregory [52] was based on material of Norwegian L. salmonis salmonis from a discontinued lab 
strain supplied by Professor Frank Nilsen of the University of Bergen in the early 2000’s (pers. made by respected authorities in the field, with whom our measurements on other species have agreed, and the salmon lice were supplied by competent scientists. We therefore believe their measurements are unlikely to be incorrect and consider the results to indicate that large variations in the salmon louse genome size occasionally arise. Such variability would not be unprecedented in copepods. Based on FCM geographically based intraspecific variations in genome size of magnitudes 1 - 9 pg have been reported in the marine calanoid copepods Calanus glacialis, “house” lake of current Max Planck Institute for Evolutionary Biology in Ploen) and Lake Baikal populations of the freshwater cyclopoid Mesocyclops leuckarti was reported [60,61]. Furthermore,

394 the genome size of the North Sea population of the calanoid Pseudocalanus elongatus decreased after being reared in the laboratory for 96 generations [62]. It would not be surprising to encounter additional examples with intraspecific genome size differences in other copepods.

397 The somatic 2C nuclear DNA contents of L. salmonis, as estimated using FCM and FIAD in 398 laboratory and wild populations (2.7 - 3.2 pg DNA per nucleus and corresponding to genome size 399 of $1.33-1.56 \mathrm{Gbps})$ are at the lower end of the range of all published values of free-living copepods, which vary more than 300 fold from 0.20 - 64.46 pg DNA per nucleus, corresponding

401 to genome sizes ranging from $195 \mathrm{Mbps}$ to $63 \mathrm{Gbps}$ (Fig. 3). Relative to the range of values in 

majority of calanoid species possessing larger or far larger genomes.

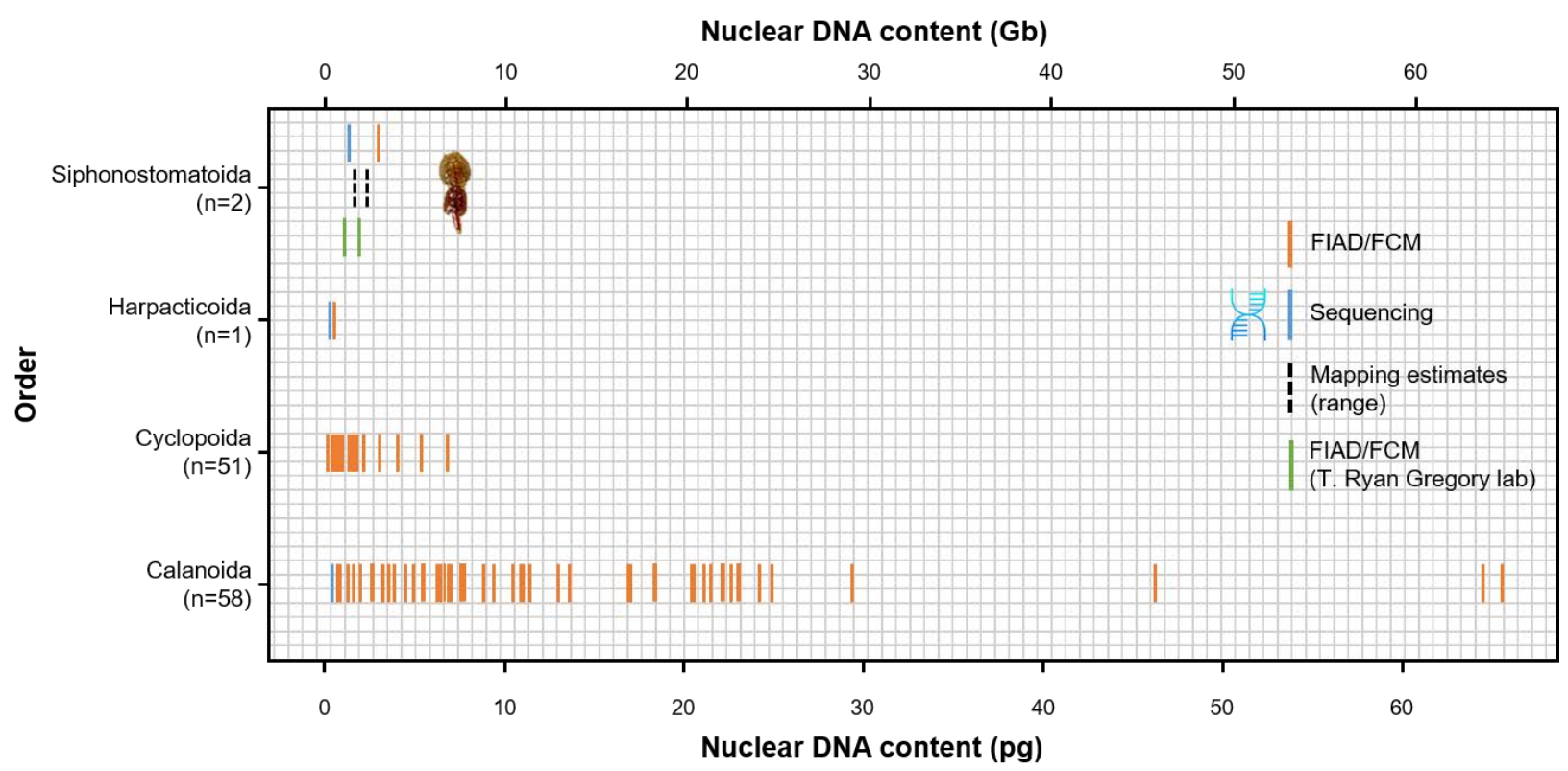

Figure 3. Somatic nuclear DNA contents of copepods. Each species is represented by a vertical bar. Estimates based on cytometric methods, genome assemblies, and mapping are presented in orange, blue, and dotted black, respectively, for the siphonostomatoid L. salmonis salmonis. The black dotted lines depict a range of values obtained for L. salmonis salmonis using mapping. FIAD and FCM measurements depicted by green vertical lines for $L$. salmonis salmonis are from Gregory [52] and Jeffery [53], respectively. FIAD (orange) and genome assembly (blue) estimates are shown for the harpacticoid T. californicus [63,64]. FIAD (orange) and genome assembly (blue) estimates for the calanoid E. affinis are the two left most vertical lines in the distribution of Calanoida [65,66]. The adult somatic genome size estimates of Cyclopoida and Calanoida (orange) were mostly acquired using FIAD and are from Gregory [52]. All estimates are presented as $2 C$ values found in the soma because some cyclopoid species and at least one calanoid species possess embryonic chromatin diminution, in which germline genome sizes (conventionally noted as $1 C$ ) substantially exceed the sizes of somatic values, thus violating the appropriateness of halving $2 C$

We speculate that the high abundance of repetitive regions in the L. salmonis salmonis genome

423 facilitates the observed variability in genome size by serving as a "size accordion” [67], and further 
425 for the rotifer Brachionus asplanchnoidis in which genome size varies by a factor of 1.9 [68]. A

426 consequence of a possible variability in genome size is that the mapping and k-mer based size

427 estimates should not be considered conclusively discredited as they are based on sequence

428 information from different wild samples or strains. For the Ls1a strain that was measured both by

429 FIAD, FCM and included in the mapping and k-mer based analysis, the discrepancy may be

430 assumed to be genuine, although the samples for cytometric analyses were sampled more than 10

431 generations after the samples for sequencing were obtained. Hence the L. salmonis salmonis

432 LSalAtl2s genome assembly [40] appears to fail to resolve $\approx 50 \%$ of the genome that is captured

433 in the cytometric measurements. There are several possible sources that may contribute to this

434 discrepancy: failure to isolate some regions of DNA, failure to capture all DNA in sequencing

435 libraries or sequencing reactions, errors introduced during the bioinformatic analyses and specific

436 challenges caused by TE’s and DNA repeats.

437 The fact that the six independent genome assemblies are congruent in content despite 438 originating from DNA purified from multiple origins of L. salmonis in different laboratories and 439 sequenced using various sequencing platforms (Illumina, 454 pyrosequencing, Oxford nanopore, 440 PacBio and Sanger) may suggest that no parts of the genome are systematically missed by the 441 purification and sequencing protocols applied. However, systematic omission of genetic regions 442 across isolation protocols or biased representations of repetitive regions cannot be excluded and 443 would yield biased or incomplete genome representations. A similar distorting effect may be 444 introduced during downstream bioinformatic analysis, for instance, by collapsing repetitive 445 regions [43]. Distinguishing between a bias in sequencing representation and bioinformatic 446 artifacts as the cause of underestimating repetitive regions is challenging. PacBio and Nanopore 447 sequencing platforms produce long reads that are commonly suggested as a tool to address 
repetitive regions. However, the two most recent $L$. salmonis salmonis assemblies were produced using PacBio (UStir_LSAA, Table 1) and Oxford nanopore combined with Illumina (UVic_Lsal_1.0, Table 1) sequencing. These did not deviate significantly in content or size from earlier assemblies and hence did not resolve the question of the missing DNA. Since there are no

452 indications that specific regions are missed in any of the assemblies (Table 2) it is possible that the 453 majority of the $\approx 800 \mathrm{Mbp}$ of “missing” DNA (cytometric based genome size minus genome assembly size) in the samples measured by FIAD and FCM in the present study is comprised of

455 TEs and DNA repeats that are not accurately captured in the assemblies. The fact that the long read based assemblies do not, at least partly, resolve the challenge may indicate that mini- and microsatellites may be dominating the missing fraction since these are considered more prone to incorrect rendering by long read sequencing than TE's [43,69]. Hence, the $\approx 1500 \mathrm{Mbp}$ genomes measured in the present study suggestively consist of $\approx 80 \%(\approx 1200 \mathrm{Mbp})$ repetitive or otherwise uncaptured regions and $\approx 20 \%(\approx 300 \mathrm{Mbp})$ non-repetitive regions.

Challenges in capturing repeated regions are likely exacerbated in mid to large size genomes. californicus and the estuarine calanoid copepod Eurytemora affinis whose $2 C$ genome sizes estimated by FIAD are 0.5 and 0.6-0.7 pg DNA per nucleus, respectively $[63,65]$. Both genome assemblies were significantly smaller by $\approx 20 \%(\sim 400 \mathrm{Mb}$ for T. californicus, $\sim 495 \mathrm{Mb}$ for E. affinis for $2 C$ values) which attributed to the inability to sequence all of the repetitive DNA [64,66]

467 (Fig. 3). While L. salmonis salmonis has a genome size at the lower range of the distribution of 468 copepods (Fig. 3), it is still two to three fold larger than T. californicus and E. affinis. A significant proportion of repetitive regions of the salmon louse genome consists of transposable elements, or

470 of unclassified repeated motifs that may in time be annotated as TEs [40]. Precisely identifying 
471 the portion of the genome that is comprised of TEs and their composition is of interest as TEs are

472 increasingly viewed as drivers of genome plasticity that facilitate the rise of new phenotypes, such

473 as acquiring insecticide resistance in fruitflies [70,71]. It may be speculated that the high

474 occurrence of repeated regions, including TEs, in the salmon louse genome may have contributed

475 to its documented ability to develop resistance towards new medicinal treatments despite a low

476 diversity of genes typically associated with detoxification and stress response [36,40,72-74]. If this

477 is the case, the use of medicines in salmon farms that harbor the majority of sea lice in parts of the

478 North Atlantic may have positively selected for high numbers of TEs and hence for a larger

479 genome size. This hypothesis is directly testable as L. salmonis onchorhynchi in the Pacific is less

480 influenced by salmon farming, owing to the large stocks of wild salmonids, and hence should 481 display a more frequent occurrence of smaller genomes.

483 Materials and Methods

484 Assembly analyses and sequencing-based genome size estimates

485 To evaluate the congruence of the six assemblies available in public databases (Table 1), while not 486 requiring them to conserve synteny, we made a script that converted the individual assemblies into 487 non-overlapping 240 bp synthetic reads thus generating 6 synthetic read libraries. These synthetic 488 reads were then mapped to each of the published assemblies using BLAST with the following 489 command line: blastn -num_threads 16 -evalue 1e-10 -outfmt 6 -num_alignments 10 -penalty -1 490 reward 1 -gapopen 3 -gapextend 2. Since the same fragment may be mapped multiple times we 491 calculated the percentage of synthetic reads that mapped and the fraction of the mapped reads that 492 mapped with >95\% identity (Table 2). 
The genome size was estimated from sequencing and assembly data using three different

494 approaches: Modal mapping extrapolation, k-mer analysis and single copy gene mapping

495 extrapolation. The assembly based estimates were derived using the LSalAtl2s assembly [40]. The

496 LSalAtl2s assembly was compared to other available assemblies (Table 1) to reveal potential

497 regions that are missing.

498 Modal mapping extrapolation is based on the assumptions that populations of non-repetitive

499 DNA sequence reads follow a Poisson distribution and this makes up the majority of DNA. By

500 finding the modal coverage and dividing the total number of sequenced bases mapped by this

501 number, we can estimate the genome size. This is done using the Lande-Waterman formula; $\mathrm{G}=$

502 NL/C, where $\mathrm{G}$ is the genome size, $\mathrm{N}$ is the number of reads, $\mathrm{L}$ is the average read length, and $\mathrm{C}$

503 is the modal coverage. The modal coverage was determined by plotting the number of sites against

504 nucleotide coverage and identifying the peak value. To facilitate this, sequence reads from the

505 GLW4, GLW13 and GLW16 libraries [40] previously published were mapped against the

506 LSalAtl2S genome assembly using Samtools [51].

507 K-mer analysis is based on the assumption that the possible words of a certain size in a genome

508 (k-mers) increase with the size of the genome. A genome consisting primarily of non-repetitive

509 DNA regions will generate an approximately random population of k-mers, and the diversity of k-

510 mers in a population of reads can be used to estimate the genome size. In the present study k-mer

511 analyses were performed using Jellyfish [50] and sequence reads from the GLW4 library derived

512 from a laboratory strain of L. salmonis salmonis [40] and libraries derived from L. salmonis

513 salmonis collected in the field. 


\section{$516 \quad$ Field and laboratory populations}

517 Specimens of L. salmonis salmonis were obtained from several sources: (1) Wild adult males and

518 females were collected from naturally infected farmed Atlantic salmon held at the sea cage

519 facilities of the Aquaculture Research Station in Tromsø (FCM Run 5); (2) An outbred laboratory

520 strain, Ls Gulen, was derived from adults collected in Ls Gulen (Norway) and reared at the Salmon

521 Louse Research Centre in Bergen (FCM Run 4); (3) The Ls Tromsø laboratory strain was

522 established by crossing adults from the Ls Gulen strain with a partially outbred strain, Ls

523 Oslofjord, originating from specimens collected in Oslofjord (Norway) and reared at the

524 Aquaculture Research Station in Tromsø (FCM runs 1-3).

\section{Collection of samples and tissue preparation}

526 Newly hatched nauplii were obtained from gravid females, crushed in cold citrate buffer [75] 527 containing 5\% dimethyl sulfoxide (DMSO), filtered through a $30 \mu$ mylon mesh and deep-frozen

528 until use. Sperm and eggs were collected from the testes and the genital segment prior to 529 fertilization, respectively, and the resulting samples briefly kept on ice prior to analysis. Somatic 530 (cuticular and subcuticular) tissues obtained from the cephalothorax (Supplemental Materials and

531 Methods Fig. 1) of adult wild or laboratory specimens were crushed, and treated in the same way 532 as the newly hatched nauplii. Specimens were squashed onto slides according to Clower and co533 workers [54] except that a freeze-cracking technique was added.

\section{Flow cytometry analysis}

535 Aliquots of target (sea lice) and internal reference (male human and/or chicken) cells were 536 analyzed using Propidium Iodide (PI) as fluorescent stain following previously reported methods 537 [76]. The mean DNA content of 5000 - 10,000 cells per sample was measured with a 538 CyFlow ${ }^{\circledR P l o i d y ~ A n a l y s e r ~ e q u i p p e d ~ w i t h ~ a ~ g r e e n ~ l a s e r . ~}$ 
539 Nuclear DNA contents of target species were estimated in relation to an assigned 2C value of 7.00

540 pgDNA/nucleus for human leukocytes and 2.50 pg DNA/nucleus for chicken erythrocytes [52]

541 according to the formula:

542 Target species nuclear DNA content $(\mathrm{pg})=($ Mean FL value of the sample $\times$ reference

$2 C$ DNA content $) \times(\text { Mean FL value of the reference })^{-1}$

\section{Feulgen image analysis densitometry}

\section{$546 \quad$ Field and laboratory populations}

547 Genome size measurements were obtained from each of three adults (females) of the Ls1a 548 laboratory strain described elsewhere [77], whose ovaries served as the source material of DNA 549 used in the nanopore DNA sequencing and six adults (three males and three females) of L. salmonis 550 salmonis from Ls Gulen laboratory strain used in the FCM studies. A single adult female was

551 collected from the wild in Copscook Bay, Maine in 2018. Specimens were immediately preserved 552 in undenatured $>95 \%$ alcohol.

\section{Feulgen staining and scanning microdensitometry}

554 All slides were squashed and stained with Schiff reagent according to previously reported methods 555 [45,54], with few modifications. Nuclei were measured using a Zeiss Axioscope A1 equipped with 556 a 63X oil objective and a Qimaging Bioquant PVI CCD camera. Scanning microdensitometric 557 software (Bioquant Image Analysis; Bioquant Life Sciences 2018 program) was used to determine 558 the IODs of the nuclear DNA contents of individual somatic nuclei. We selected for measurement 559 only nuclei that possessed a granular and slightly diffuse appearance and lacked visible pink 560 background; these nuclei were found mostly at the perimeter or outside the carapace (Fig. 2c,d).

561 Nuclei with relatively small areas and dense staining indicating DNA compaction (Fig. 2e) or very 
562 diffuse and large areas (Fig. 2f) are less likely to provide accurate measurements. The Bioquant

563 software used to measure IODs has a conservative estimate of resolution of 0.5 pg DNA per

564 nucleus according to the manufacturer. The mean IOD value of the hen was used to convert the

565 IODs of each L. salmonis salmonis specimen to picograms, using the following equation:

$$
\mathrm{Pg}_{\mathrm{c}}=\left(\mathrm{pg}_{\mathrm{s}} / \mathrm{IOD}_{\mathrm{s}}\right) \times \mathrm{IODc}
$$

where $\mathrm{pg}_{\mathrm{c}}$ is the unknown amount of pg DNA per nucleus of L. salmonis salmonis $\mathrm{pg}_{\mathrm{s}}, 2.5 \mathrm{pg}$ is

the amount of DNA in the standard hen nucleus, $\mathrm{IOD}_{\text {s }}$ is the average IOD value of the hen, and

569 IODc is the IOD value of L. salmonis. Photographs were taken at 100X magnification with a Nikon

570 Eclipse Ti-2 microscope equipped with a PlanApo objective (N.A. 1.45) and QImaging DS RI2

571 camera.

572 Reference standards for conversion of integrated optical density (IOD) units to picograms (pg)

573 included mutant white eyed female Drosophila melanogaster (0.40 pg DNA per nucleus),

574 erythrocytes of hen Gallus domesticus (2.5 pg DNA per nucleus) and trout Onycorhynchus mykiss

575 (5.2 pg DNA per nucleus), and leucocytes of male human Homo sapiens (7.0 pg DNA per nucleus)

576 whose values were based on previous works [78,79] and the Animal Genome Size Database [52].

577 The calibration curve computed for standards in the staining batch containing the Ls1a strain

578 yielded an $\mathrm{R}^{2}=0.997$ (Supplementary Methods Fig. 2), indicating quantitative staining over a

579 range of $0.40-7.0$ pg DNA per nucleus. Only hen and trout standards (Fig. 2a,b) were used in the

580 staining batch with Ls Gulen and Maine specimens.

581 The mean nuclear DNA contents are reported as $2 C$ values in picograms (pg) and converted to 582 gigabase $(\mathrm{Gb})$ pairs $(1 \mathrm{pg}$ DNA $=0.978 \mathrm{~Gb})$ for both FCM and FIAD derived estimates [80]. 


\section{Statistical analyses}

586 Differences in nuclear DNA content of somatic tissues between LsTromsø nauplii (FCM Run

5871 and 2) and $L s$ Gulen germinal (eggs and sperm) or somatic tissues of LsTromsø and $L s$ Gulen

588 adult males and females (FCM Run 3-4), as well as those of $L s$ Gulen adults obtained using FIAD,

589 were analyzed by Students $t$-test. Analysis of variance (ANOVA) was used to detect significant

590 differences in nuclear DNA content of somatic tissue of adult wild caught and laboratory

591 LsTromsø strain L. salmonis salmonis (FCM Run 5) using fluorescence (FL) PI values as

592 dependent variable and gender and strain (laboratory or wild) as factors. In Exploratory Data

593 Analysis (EDA), Grubbs’ test was used to detect presence of outliers and Levene's and Shapiro-

594 Wilk tests were used to test homogeneity of variances among groups. Statistical analyses were

595 performed using IBM SPSS Statistics v.25 software. Differences were accepted as significant when

$596 \mathrm{P}<0.05$. Data are reported as mean \pm standard error (SE). The Shapiro-Wilks test applied to nuclei

597 within each of 10 specimens measured using FIAD revealed no departures from normality.

598 Differences between male and female genome sizes based on FIAD were tested using two sample, 599 two tailed Student $t$-tests.

600

601 References

602 1. McClintock, B. The significance of responses of the genome to challenge. Science 226, 792-

$603 \quad$ 801; 10.1126/science.15739260 (1984).

604 2. Gregory, T.R. The Evolution of the Genome (ed. Gregory, T.) 740 pp. (Elsevier, Academic 605 Press, 2005). 
3. Markov, A.V., Anisimov, V.A. \& Korotayev, A.V. Relationship between genome size and organismal complexity in the lineage leading from prokaryotes to mammals. Paleontol. J. 44, 363-373 (2010).

4. Choi. I-Y., Kwon, E-C. \& Kim, N.S. The C-and G-value paradox with polyploidy repeatomes, introns, phenomes, and cell economy. Genes \& Genomics 42, 699-714 (2020).

5. Wyngaard, G.A., Rasch, E.M., Manning, N.M., Gasser, K. \& Domangue, R. The relationship between genome size, development rate, and body size in copepods. Hydrobiologia 532, 123137 (2005).

6. Leinaas, H.P., Jalal, M., Gabrielsen, T.M. \& Hessen, D.O. Inter- and intraspecific variation in body- and genome size in calanoid copepods from temperate and arctic waters. Ecol. Evol. 6, 5585-5595 (2016).

7. Hultgren, K.M., Jeffery, N.W., Moran, A. \& Gregory, T. R. Latitudinal variation in genome size in crustaceans. Biol. J. Linn. Soc. 123, 348-359 (2018).

8. Gregory, T.R. Coincidence, coevolution or causation? DNA content, cell size, and the $C$-value enigma. Biol. Rev. 76, 65-101 (2001).

9. Elliott, T.A. \& Gregory, T.R. What is in a genome? The C-value enigma and the evolution of eukaryotic genome content. Phil. Trans. R. Soc. B. 370, 20140441; 10.1098/rstb.2014.0331 (2015).

10. Bennett, M.D. \& Leitch, I.J. Genome size evolution in plants. In: Gregory, T.R. The Evolution of the Genome (ed. Gregory, T.), 89-162 (Elsevier, Academic Press, 2005).

11. Hessen, D.O., Daufresne, M. \& Leinaas, H.P. Temperature-size relations from the cellulargenomic perspective. Biol. Rev. 88, 476-489 (2013). 
12. Ivancevic, A.M., Kortschak, R.D., Bertozzi, T. \& Adelson, D.L. Horizontal transfer of BovB and L1 retrotransposons in eukaryotes. Genome Biol. 19, 10.1186/s13059-018-1456-7 (2018).

13. Bourque, G. et al. Ten things you should know about transposable elements. Genome Biol. 19, 199; 10.1186/s13059-018-1577-z (2018).

14. Eickbush, T.H. \& Furano, A.V. Fruit flies and humans respond differently to retrotransposons.

633 Curr. Opin. Genet. Dev. 12, 669-674; 10.1016/s0959-437x(02)00359-3 (2002).

634 15. Rech, G.E. et al. Stress response, behavior, and development are shaped by transposable

635 element-induced mutations in Drosophila. PLoS Genet. 15, e1007900;

636 10.1371/journal.pgen.1007900 (2019).

637 16. Kapun, M. et al. Genomic analysis of European Drosophila melanogaster populations reveals

638 longitudinal structure, continent-wide selection, and previously unknown DNA viruses. Mol.

639 Biol. Evol, 37, 2661-2678; 10.1093/conphys/coz072 (2020).

640 17. Hessen, D.O., Ventura, M. \& Elser, J.J. Do phosphorus requirements for RNA limit genome 641 size in crustacean zooplankton? Genome 51, 685-691 (2008).

642 18. Bullejos, F.J., Carrillo, P., Gorokhova, E., Medina-Sanchez, J.M. \& Villar-Argaiz, M. Nucleic 643 acid content in crustacean zooplankton: bridging metabolic and stoichiometric predictions. $644 \quad$ PLoS ONE 9, e86493; 10.1371/journal.pone.0086493 (2014).

645 19. Tørrissen, O. et al. Salmon lice - impact on wild salmonids and salmon aquaculture. J. Fish 646 Dis. 36, 171-194 (2013).

647 20. Vollset, K.W. et al. Disentangling the role of sea lice on the marine survival of Atlantic salmon. 
21. Skern-Mauritzen, R., Torrissen, O. \& Glover, K.A. Pacific and Atlantic Lepeophtheirus salmonis (Kroyer, 1838) are allopatric subspecies: Lepeophtheirus salmonis salmonis and L. salmonis oncorhynchi subspecies novo. BMC Genet. 15, 32; 10.1186/1471-2156-15-32 (2014).

652 22. Marincovich, L. \& Gladenkov, A.Y. Evidence for an early opening of the Bering Strait. Nature 397,149-151 (1999).

654 23. Yazawa, R. et al. EST and mitochondrial DNA sequences support a distinct Pacific form of salmon louse, Lepeophtheirus salmonis. Mar. Biotechnol. 10, 741-749 (2008).

24. Bui, S., Oppedal, F., Stien, L. \& Dempster, T. Sea lice infestation level alters salmon swimming depth in sea-cages. Aquacult. Environ. Interact. 8, 429-435 (2016).

25. Fjelldal, P.G., Hansen, T.J., Karlsen, Ø. \& Wright D.W. Effects of laboratory salmon louse infection on Arctic char osmoregulation, growth and survival. Conserv. Physiol. 7, coz072; 10.1093/conphys/coz072 (2019).

664 27. Brooker, A.J., Skern-Mauritzen, R. \& Bron, J.E. Production, mortality, and infectivity of 665 planktonic larval sea lice, Lepeophtheirus salmonis (Kroyer, 1837): current knowledge and 666 implications for epidemiological modelling. ICES J. Mar. Sci. 75, 1214-1234 (2018).

667 28. Forseth, T. et al. The major threats to Atlantic salmon in Norway. ICES J. Mar. Sci. 74, 1496$668 \quad 1513(2017)$

669 29. Murray, A.G. \& Moriarty, M. A simple modelling tool for assessing interaction with host and 670 local infestation of sea lice from salmonid farms on wild salmonids based on processes 
operating at multiple scales in space and time. Ecol. Model 443, 10.1016/j.ecolmodel.2021.109459 (2020).

673 30. Sandvik, A.D. et al. The development of a sustainability assessment indicator and its response 674 to management changes as derived from salmon lice dispersal modelling. ICES J. Mar. Sci., 675 fsab077; 10.1093/icesjms/fsab077 (2021).

676 31. Thomson, C.R. et al. Illuminating the planktonic stages of salmon lice: A unique fluorescence 677 signal for rapid identification of a rare copepod in zooplankton assemblages. J. Fish Dis. 44, 863-879 (2021).

32. Glover, K.A. et al. Population genetic structure of the parasitic copepod Lepeophtheirus salmons throughout the Atlantic. Mar. Ecol. Prog. Ser. 427:161-172 (2011).

33. Besnier, F. et al. Human-induced evolution caught in action: SNP-array reveals rapid amphiatlantic spread of pesticide resistance in the salmon ecotoparasite Lepeophtheirus salmonis. BMC Genomics 15, 937; 10.1186/1471-2164-15-937 (2014).

34. Fjørtoft, H.B. et al. Salmon lice sampled from wild Atlantic salmon and sea trout throughout 685 Norway display high frequencies of the genotype associated with pyrethroid resistance. Aquacult. Env. Interact. 11, 459-468 (2019). towards hydrogen peroxide found in the salmon louse Lepeophtheirus salmonis in Norway, Aquacult. Rep. 1, 37-42 (2015).

691 salmonis pre-dates organophosphate use in salmon farming. Sci Rep. 7(1), 12349; 10.1038/s41598-017-12384-6 (2017). 
37. Skern-Mauritzen, R., Frost, P., Hamre, L.A., Kongshaug, H. \& Nilsen, F. Molecular

694 characterization and classification of a clip domain containing peptidase from the ectoparasite

695 Lepeophtheirus salmonis (Copepoda, Crustacea). Comp. Biochem. Physiol. B Biochem Mol.

696 Biol. 146(2), 289-298 (2007).

697 38. Eichner, C. et al. Characterization of a novel RXR receptor in the salmon louse

698 (Lepeophtheirus salmonis, Copepoda) regulating growth and female reproduction. BMC Genomics 16, 81; 10.1186/s12864-015-1277-y (2015).

39. Øvergård, A-C. et al. Exocrine glands of Lepeophtheirus salmonis (Copepoda: Caligidae):

701 Distribution, developmental appearance, and site of secretion. J. Morphol. 277, 1616-1630;

$702 \quad$ 10.1002/jmor.20611 (2016).

703 40. Skern-Mauritzen, R. et al. The salmon louse genome: copepod features and parasitic 704 adaptations. bioRxiv Preprint at https://doi.org/10.1101/2021.03.15.435234 (2021).

705 41. Messmer, A.M. et al. A 200K SNP chip reveals a novel Pacific salmon louse genotype linked 706 to differential efficacy of emamectin benzoate. Mar. Genom. 40, 45-57 (2018).

707 42. Treangen, T.J. \& Salzberg, S.L. Repetitive DNA and next-generation sequencing, 708 computational challenges and solutions. Nat. Rev. Genet. 13, 36-44 (2012).

709 43. Tørresen, O.K. et al. Tandem repeats lead to sequence assembly errors and impose multi-level 710 challenges for genome and protein databases. Nucleic Acids Res. 47, 10994-11006 (2019).

711 44. Rasch, E.M. Feulgen-DNA cytophotometry for estimating C values. Methods Mol. Biol. 247, 712 163-201 (2004).

713 45. Hardie, D.C., Gregory, T.R. \& Hebert, P.D.N. From pixels to picograms: A beginner's guide 714 to genome quantification by Feulgen image analysis densitometry. J. Histochem. Cytochem. $715 \quad$ 50, 725-749 (2002). 
46. Danzmann, R.G. et al. A genetic linkage map for the salmon louse (Lepeophtheirus salmonis): evidence for high male:female and inter-familial recombination rate differences. Mol. Genet. Genome. 294, 343-363 (2019).

47. Eichner, C., Dondrup, M. \& Nilsen, F. RNA sequencing reveals distinct gene expression patterns during the development of parasitic larval stages of the salmon louse (Lepeophtheirus

48. Heggland, E.I. et al. A scavenger receptor B (CD36)-like protein is a potential mediator of intestinal heme absorption in the hematophagous ectoparasite Lepeophtheirus salmonis. Sci.

49. Wellcome Trust. Sharing data from large-scale biological research projects: A system of

50. Marcais, G. \& Kingsford, C. A fast, lock-free approach for efficient parallel counting of tripartite responsibility. https://wellcome.org/sites/default/files/wtd003207_0.pdf (2003). occurrences of k-mers. Bioinformatics 27(6), 764-770 (2011).

51. Li, H. \& Durbin, R., Fast and accurate short read alignment with Burrows-Wheeler transform. Bioinformatics 25, 1754-1760; doi:10.1093/bioinformatics/btp324 (2009).

52. Gregory, T.R. Animal Genome Size Database. http://www.genomesize.com (2021).

53. Jeffery, N.W. Genome size diversity and evolution in the Crustacea. Ph.D Thesis, University of Guelph; 257 pp. https://atrium.lib.uoguelph.ca/xmlui/handle/10214/9216 (2015).

734 54. Clower, M.K., Holub, A.S., Smith, R.T. \& Wyngaard, G.A. Embryonic development and a quantitative model of programmed DNA elimination in Mesocyclops edax (S.A. Forbes, 1891) (Copepoda: Cyclopoida). J. Crustac. Biol. 36, 661-674 (2016). 585 (2006). 
56. McLaren, I.A. \& Marcogliese, D.J. Similar nuclear numbers among copepods. Can. J. Zool. 61, 721-724 (1983).

57. Jeffery, N.W., Jardine, C.B. \& Gregory, T.R. A first exploration of genome size diversity in sponges. Genome 56, 451-456 (2013).

58. Pflug, J.M., Holmes, V.R., Burrus, C., Johnston, J.S. \& Maddison, D.R. Measuring Genome Sizes Using Read-Depth, k-mers, and Flow Cytometry: Methodological Comparisons in

59. Polinski, J.M. et al. The American lobster genome reveals insights on longevity, neural, and Beetles (Coleoptera). G3 (Bethesda) 10(9), 3047-3060; 10.1534/g3.120.401028 (2020).

60. Rasch, E.M. \& Wyngaard, G.A. Genome sizes of cyclopoid copepods (Crustacea): evidence of evolutionary constraint. Biol. J. Linn. Soc. 87, 625-635 (2006).

61. Ivankina, E.A. et al. Cytophotometric Determination of Genome Size in Two Species of Cyclops of Lake Baikal (Crustacea: Copepoda, Cyclopoida) in Ontogenetic Development. Cell

62. Escribano, R., McLaren, I.A. \& Klein Breteler, W.C.M. Innate and acquired variation of Tissue Biol. 7, 192-199 (2013). nuclear DNA contents of marine copepods. Genome 35, 602-610 (1992).

63. Wyngaard, G.A. \& Rasch, E.M. Patterns of genome size in the copepoda. Hydrobiologia 417, 43-56 (2000).

64. Barreto, F.S. et al. Genomic signatures of mitonuclear coevolution across populations of 761 Tigriopus californicus. Nat. Ecol. Evol. 2, 1250-1257 (2018).

65. Rasch, E.M., Lee, C.E. \& Wyngaard, G.A. DNA-Feulgen cytophotometric determination of genome size for the freshwater invading copepod Eurytemora affinis. Genome 47, 559-564 (2004). 
66. Eyun, S-I. et al. Evolutionary history of chemosensory-related gene families across the Arthropoda. Mol. Biol. Evol. 34, 1838-1862 (2017).

67. Kapusta, A., Suh, A. \& Feschotte, Dynamics of genome size evolution in birds and mammals. Proc. Natl. Acad. Sci. USA 108, E1460-E1469 (2017).

68. Stelzer, C-P., Pichler, M., Stadler, P., Hatheuer, A. \& Riss, S. Within-population genome size variation is mediated by multiple genomic elements that segregate independently during

69. Liljegren, M.M., de Muinck, E.J. \& Trosvik, P. Microsatellite length scoring by Single Molecule Real Time Sequencing - Effects of sequence structure and PCR Regime. PLoS ONE 11(7), e0159232; 10.1371/journal.pone.0159232 (2016).

70. Pimpinelli, S. \& Piacentini, L. Environmental change and the evolution of genomes: Transposable elements as translators of phenotypic plasticity into genotypic variability. Funct. Ecol. 34, 428-441; 10.1111/1365-2435.13497 (2020).

71. Chung, H. et al. Cis-regulatory elements in the Accord retrotransposon result in tissue-specific expression of the Drosophila melanogaster insecticide resistance gene Cyp6g1. Genetics 175, 1071- 1077; 10.1534/genetics.106.066597 (2007).

72. Coates, A. et al. Evolution of salmon lice in response to management strategies: a review. Rev. Aquacult. 13, 1397-1422; 10.1111/raq.12528 (2021).

73. Besnier, F. et al. Identification of quantitative genetic components of fitness variation in farmed, hybrid and native salmon in the wild. Heredity 115, 47-55; 10.1038/hdy.2015.15 (2015).

74. Aaen, S.M., Helgesen, K.O., Bakke, M.J., Kaur, K. \& Horsberg, T.E. Drug resistance in sea lice: a threat to salmonid aquaculture. Trends Parasitol. 31, 72-81 (2015). 
75. Vindeløv, L.L., Christensen I.J. \& Nissen, N.I. A detergent-trypsin method for the preparation of nuclei for flow cytometric DNA analysis. Cytometry 3, 323-327 (1983).

76. Tiersch, T.R., Chandler, R.W., Kallman, K. \& Wachtel, S.S. Estimation of nuclear DNA content by flow cytometry in fishes of the genus Xiphophorus. Comp. Biochem. Physiol. B 94,

77. Hamre, L.A., Glover, K.A. \& Nilsen, F. Establishment and characterisation of salmon louse (Lepeophtheirus salmonis (Kroyer 1837)) laboratory strains. Parasitol. Int. 58, 451-460 (2009).

78. Mulligan, P.K. \& Rasch, E.M. The determination of genome size in male and female germ cells of Drosophila melanogaster by DNA-Feulgen cytophotometry. Histochemistry 66, 11-

79. Rasch, E.M. DNA “standards” and the range of accurate DNA estimates by Feulgen absorption microspectrophotometry. In: Advances in Microscopy, Progress in Clinical and Biological Research (eds. Cowden, R.R. \& Harrison, S.H.), 196, 137-166 (Alan R. Liss, Inc., 1985).

801

80. Doležel, J., Bartoš, J., Voglmayr, H. \& Greilhuber, J. Nuclear DNA and genome size of trout and human. Cytometry 51, 127-128 (2003). preparation of plate, Harrison Giknovorian for technical assistance with squashing and Feulgen reaction, Emilly Schutt for preparation of the graph, Ken Roth for supplying the human blood, 
808 Michaël Bekaert, Tyler Elliott, Ryan Gregory, Nick Jeffery, and Ben Koop for critical discussions.

809 Work at JMU was supported by NIH 1R15GM104868 and NSF- DBI-1725855 to GAW and

810 others, NSF-DEB 1948267 to GAW and a grant to GAW from the James Madison University

811 Program of Grants for Faculty Assistance. The publication charges for this article have been

812 funded by a grant to SP from the publication fund of UiT, The Arctic University of Norway. The

813 authors are grateful to Anette Hustad, Linn Svendheim and Svenn Rune Hansen at the Aquaculture

814 Research Station in Tromsø and to Sussie Dalvin (IMR, Bergen) for sea lice samples collection.

815 We acknowledge the veterinarian Diogo Costa Ramos Da Rocha Marques for supplying the 816 chicken blood and Goran Kauric at the University Hospital of North Norway (UNN, Tromsø) for 817 processing the human blood samples.

\section{Author contributions}

820 GAW, RSM and SP - conceptualized and designed the work. GAW and SP - conducted cytogenetic

821 (FIAD, Flow Cytometry) analyses and data handling. RSM and KM - performed bioinformatic 822 analyses. GAW, RSM, KM and SP - drafted and wrote the main manuscript. RP developed the 823 freeze-cracking method for FIAD measurements. All authors reviewed the manuscript.

\section{Competing interests’ statement}

826 The authors declare that they have no competing interests. 